\title{
Gut microbiota derived metabolites in cardiovascular health and disease
}

\author{
Zeneng Wang ${ }^{\bowtie}$, Yongzhong Zhao \\ Department of Cellular and Molecular Medicine, Lerner Research Institute, Cleveland Clinic, Cleveland, OH 44195, USA \\ $\triangle$ Correspondence: wangz2@ccf.org (Z. Wang) \\ Received March 16, 2018 Accepted April 16, 2018
}

\begin{abstract}
Trillions of microbes inhabit the human gut, not only providing nutrients and energy to the host from the ingested food, but also producing metabolic bioactive signaling molecules to maintain health and elicit disease, such as cardiovascular disease (CVD). CVD is the leading cause of mortality worldwide. In this review, we presented gut microbiota derived metabolites involved in cardiovascular health and disease, including trimethylamine- $\mathrm{N}$-oxide (TMAO), uremic toxins, short chain fatty acids (SCFAs), phytoestrogens, anthocyanins, bile acids and lipopolysaccharide. These gut microbiota derived metabolites play critical roles in maintaining a healthy cardiovascular function, and if dysregulated, potentially causally linked to CVD. A better understanding of the function and dynamics of gut microbiota derived metabolites holds great promise toward mechanistic predicative CVD biomarker discoveries and precise interventions.
\end{abstract}

KEYWORDS gut microbiota, metabolites, cardiovascular health, cardiovascular disease

\section{INTRODUCTION}

There is a big gap in interpreting the molecular physiology by using the human genome coding capacity encompassing 23,000 coding genes (Gonzaga-Jauregui et al., 2012). The human gut is inhabited with 100 trillion microbes, with the majority as bacteria and archaea, fungi and microeukaryotes (Wampach et al., 2017). Almost 10 million coding genes of the microbiota have been uncovered, greatly expanding the

Electronic supplementary material The online version of this article (https://doi.org/10.1007/s13238-018-0549-0) contains supplementary material, which is available to authorized users. coding capacity of our human as a superorganism (Qin et al., 2010; Li et al., 2014). Gut microbiota are essential to human health in many aspects, such as training intestinal epithelial barrier, modulating immuno-function, digesting host indigestible nutrients, producing vitamins and hormones and preventing pathogenic bacterium colonization (Schuijt et al., 2016). For a healthy subject, gut microbiota homeostasis is maintained with pathogenic microbe growth under control. Once the balance breaks, i.e., dysbiosis, pathogenic microbes thrive, leading to gut related diseases, such as inflammatory bowel disease (IBD), obesity, allergic disorders, diabetes mellitus, autism, colorectal cancer and cardiovascular disease (DeGruttola et al., 2016; Yang et al., 2015; Battson et al., 2017). Fecal microbiota transplantation has shown great efficacy in managing Clostridium difficile infection and Crohn's disease (Bakken et al., 2013; Paasche 2013; Zhang et al., 2013). In animal model, fecal microbiota transplant to germ free mice recipients has been shown to transmit obesity and atherosclerosis susceptibility, suggesting the great potential of fecal microbiota transplantation in treating a panel of complex disease (Gregory et al., 2015; Turnbaugh et al., 2006). In addition, the prebiotic and probiotic administrations also show beneficial effects in optimizing gut microbiota community structure and preventing dysbiosis (Hamilton et al., 2017; Anhe et al., 2015; Delgado et al., 2014; Kouchaki et al., 2017).

The association between gut microbiota and health has become a hot topic, the rapid progress in this field is ascribed to next generation sequencing methods as well as the ease of maintaining germ free mice (Mardis, 2008; Bhattarai and Kashyap, 2016).

Gut microbes are involved in the biosynthesis of an array of bioactive compounds, contributing to normal human physiological functions or eliciting disease (Fan et al., 2015; Wang et al., 2011). CVD is the leading cause of death worldwide, the association with gut microbiota has been reported in recent few years, which is mediated by gut 
microbiota derived metabolites (Wang et al., 2011; Tang et al., 2013; Koeth et al., 2013). In this review, we listed gut microbiota derived metabolites and their clinical relevance in cardiovascular health and disease pathogenesis.

\section{TRIMETHYLAMINE N OXIDE (TMAO)}

Gut microbiota cleave some trimethylamine containing compounds to produce trimethylamine (TMA), which can be further oxidized as trimethylamine $\mathrm{N}$ oxide (TMAO) in the host liver by flavin monooxygenase (FMOs) (Wang et al., 2011; Koeth et al., 2013). FMO3 is the most abundant enzyme in the liver, while FMO1 and FMO2 can also catalyze the oxidation of TMA (Bennett et al., 2013). In some patients with loss-of-function mutation of the FMO3 gene, accumulated TMA in vivo spreads all over the body and is released in sweat and breath, which is a genetic disease named fish odor syndrome (Dolphin et al., 1997; Ulman et al., 2014). The precursors for gut microbiota to produce TMA include TMAO, choline, phosphatidylcholine, carnitine, $\mathrm{Y}$-butyrobetaine, betaine, crotonobetaine and glycerophosphocholine, all of which are abundant in animal diet (Koeth et al., 2013; Wang et al., 2015; Rausch et al., 2013).

The diet-gut microbiota-liver to TMAO biosynthesis constitutes a metaorganismal pathway (Fig. 1), including four enzymes involved in production of TMA, choline-TMA lyase (cutC/D) (Craciun et al., 2014), carnitine monooxygenase (cntA/B) (Zhu et al., 2014), betaine reductase (Andreesen, 1994), and TMAO reductase (Pascal et al., 1984).
Furthermore, yeaW/X, highly homologous to $\mathrm{cnt} A / \mathrm{B}$, also contributes to production of TMA. Besides carnitine, yeaW/X can also use choline, $\mathrm{Y}$-butyrobetaine and betaine as substrates to produce TMA (Koeth et al., 2014).

CutC/D has been crystalized and the enzymatic mechanism has been demonstrated. CutD, as a radical S-adenosylmethionine-activatase, activates CutC, resulting in formation of a glycyl radical. In CutC, the glycyl radical abstracts the hydrogen from cysteine to produce a thiyl radical and further captures the hydrogen atom from choline at $\mathrm{C} 1$ position, resulting in molecular rearrangement and TMA production. (Craciun et al., 2014; Kalnins et al., 2015; Bodea et al., 2016). CntA/B is a two-component Rieske-type oxygenase/reductase, carnitine can be first oxidized followed by cleavage at C-N bond by CntA/B to produce TMA and malic semialdehyde (Zhu et al., 2014). Hundreds of bacterial strains are predicted to express cutC/D or cntA/ByeaW/X in the human gut (Fig. 2A, 2B, 2C and Table S1) (Rath et al., 2017; Martinez-del Campo et al., 2015). Proteus mirabilis is a cutC/D expressing bacterium species and since it can grow under both aerobic and anaerobic conditions, it has been used as a model to screen choline trimethylamine lyase inhibitors (Wang et al., 2015). It is most likely the gene tree of cutC substantially differs from species tree, e.g., species of the same genus but with distinct topology for Klebsiella (Fig. 2D). FMO3 expression in mice is regulated by sex hormone, repressed by androgens and stimulated by estrogens (Bennett et al., 2013).

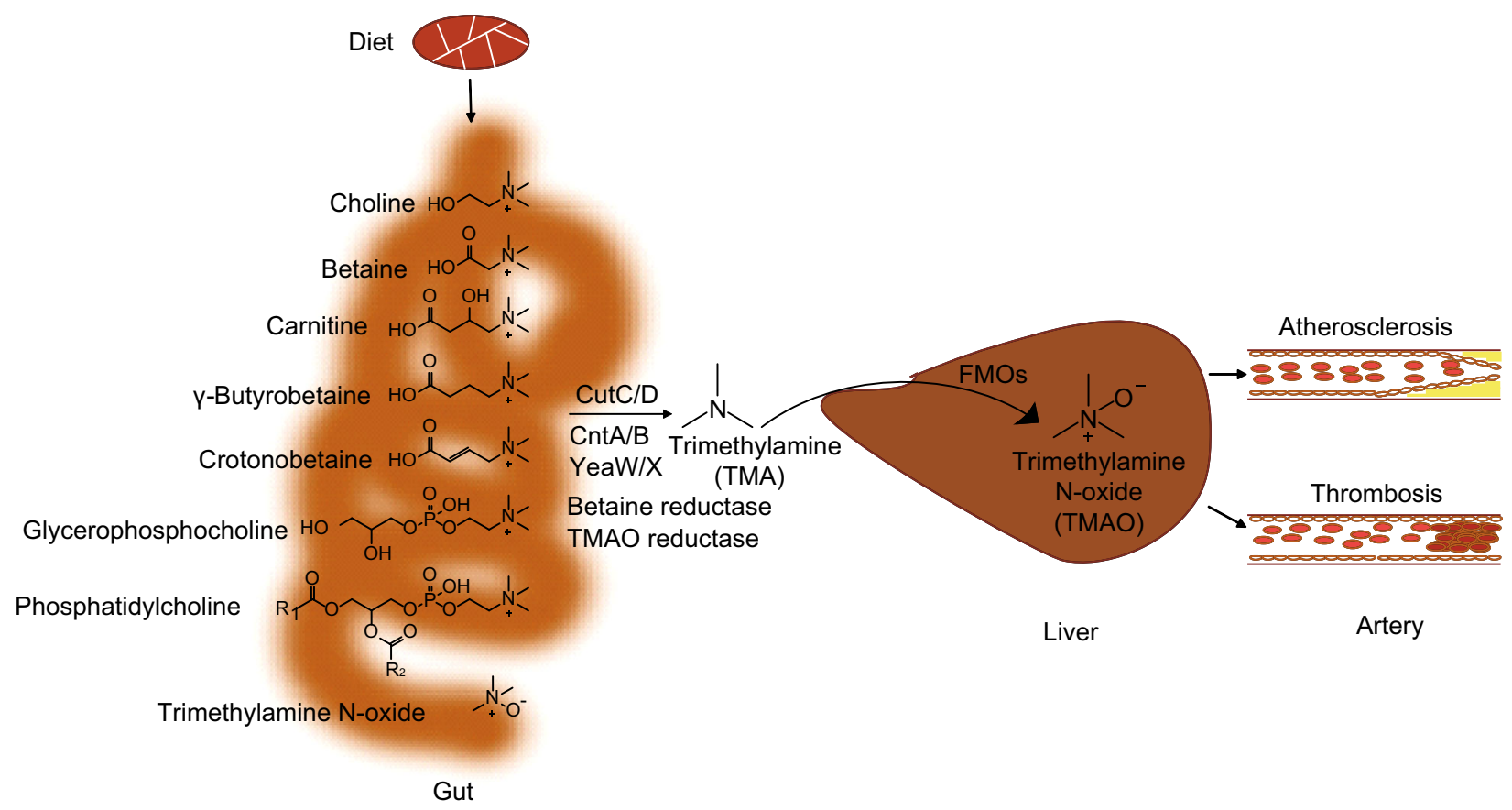

Figure 1. Metaorganismal pathway of trimethylamine $\mathrm{N}$ oxide (TMAO) biosynthesis and linking to cardiovascular disease. FMOs, Flavin monooxygenases. R1, R2, $\mathrm{CH}_{3}\left(\mathrm{CH}_{2}\right) \mathrm{n}_{1}(\mathrm{CH}=\mathrm{CH}) \mathrm{n}_{2}, \mathrm{n}_{2}=0,1,2 \ldots .6, \mathrm{n}_{1}+2 \mathrm{n}_{2}=15,17,19,21$. 
A

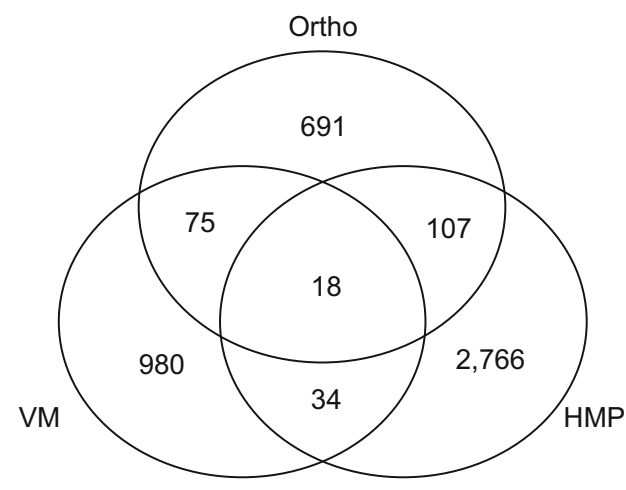

C

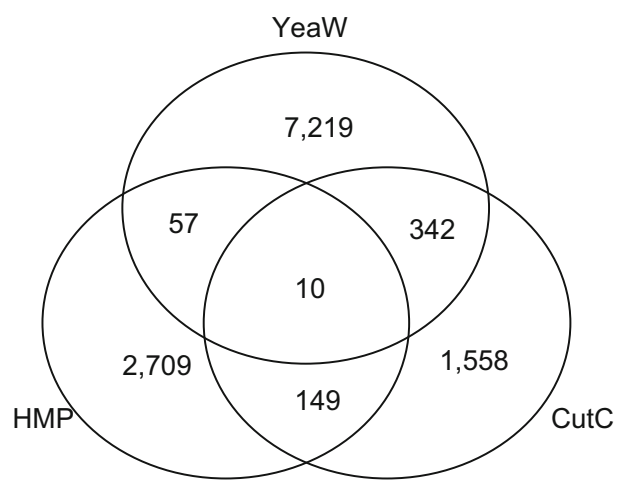

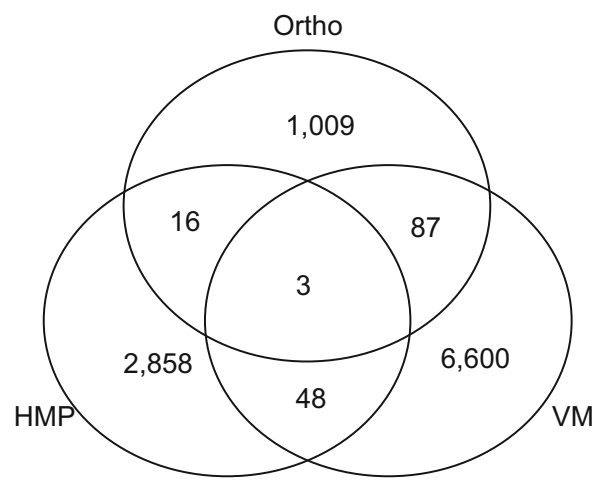

D

71 Aeromonas hydrophila AL09-71

71 Aeromonas hydrophila pc104A

98. Aeromonas hydrophila ML09-119

76. Aeromonas hydrophila J-I

100. Aeromonas hydrophila AH10

51 - Aeromonas hydrophila YL17

Klebsiella aerogenes KCTC 2190

100 Klebsiella pneumoniae 342

o1 Klebsiella varriicola DSM 15968

Escherichta coli O6:K15:H31 536 (UPEC)

56 Raoultella ornithinolytica B6

77 Klebsiella michiganensis KCTC 1686

98100 Klebsiella axytoca KONIH 1

100 I Proteus mirabilis BB2000

100

Scrraha fonticola DSM 4576

100 Serratia fonticola GS2

- Pectobactenum atrosepticum SCR 11043

100 Pectobacterium parmeritieri WF P163

100 Pectobactcrium sp. SCC3193 Desulfovibrio desulfuricans ATCC 27774 Enterabacteriaceae bacterium FGI 57

\section{$\stackrel{\longmapsto}{0.050}$}

Figure 2. Predicted bacteria strains encoding the cutC/yeaW/cntA TMA lyases. (A) Predicted bacteria strains encoding cutC gene. Abbreviation, HMP, the NIH Human Microbiome Project (Data release 1.1, September 26, 2017 e), Ortho, cutC encoding gene of OrthoDB (http://www.orthodb.org/v9.1/) (Zdobnov et al., 2017), and VM, data from the reference (Rath et al., 2017). (B) Predicted bacteria stains encoding yeaW/cntA genes. Ortho, yeaW encoding gene of OrthoDB. (C) Predicted bacterial strains encoding both yeaW and cutC. (D) Phylogenetic gene tree of cutC encoding strains. The Neighbor-Joining tree was built with MEGA7 (Kumar et al., 2016).

Many lines of evidence show the pro-atherogenic property of TMAO. Circulating TMAO level is associated with prevalence of cardiovascular disease and can independently predict incident risk for major adverse cardiac events, including myocardial infarction, stroke or death after adjustment for traditional cardiac risk factors and renal function (Wang et al., 2011; Tang et al., 2013). Circulating choline, betaine and carnitine levels also have been shown associated with prevalence of cardiovascular disease and can predict incident risk for major adverse cardiac events. However, their prognostic values are dependent on the serum TMAO levels (Koeth et al., 2013; Wang et al., 2014). ApoE-null mice fed a chow diet supplemented with TMAO appear to have an enhanced aortic lesion. Furthermore, choline can also increase aortic lesion and promote atherosclerosis but indispensable to gut microbiota, indicating the causal of TMAO in atherosclerosis (Wang et al., 2011). In vitro animal models have also confirmed the prothrombotic effect of TMAO by enhancing platelet aggregation (Zhu et al., 2016). Consistently, oral choline supplementation increases fasting TMAO levels and also enhances platelet aggregation (Zhu et al., 2017).

Mechanisms by which how TMAO can promote atherosclerosis and thrombosis have been studied at the molecular level. TMAO activates vascular smooth muscle cell and endothelial cell MAPK, nuclear factor-KB (NF-KB) signaling, leading to inflammatory gene expression and endothelial cell adhesion of leukocytes (Seldin et al., 2016). Meanwhile, TMAO can also activate the NLRP3 inflammasome (Sun et al., 2016; Boini et al., 2017; Chen et al., 2017). 
TMAO in vivo can increase scavenger receptor, CD36 and SR-A1 expression, leading to more uptake of modified LDL for macrophage to form foam cell (Wang et al., 2011). On the other hand, TMAO decreases expression of two key enzymes, CYP7A1 and CYP27A1, essential for bile acid biosynthesis and multiple bile acid transporters (OATP1, OATP4, MRP2 and NTCP) in the liver, which decreases bile acid pool, resulting in decreased reverse cholesterol efflux (Koeth et al., 2013). Moreover, TMAO increases endoplasmic recticulum calcium release in platelet cell, consequently leading to platelet aggregation and thrombosis (Zhu et al., 2016).

The association between TMAO and cardiovascular disease has been highlighted in different groups by using different cohorts worldwide (Troseid et al., 2015; Suzuki et al., 2016, 2017; Schuett et al., 2017). Besides cardiovascular disease, TMAO also contributes to renal insufficiency and mortality risk in chronic kidney disease, type II diabetes, insulin resistance, non-alcoholic fatty liver disease and colorectal cancer as well (Tang et al., 2015; Shan et al., 2017; Oellgaard et al., 2017; Kummen et al., 2017). These studies indicate circulating TMAO levels has the potential to be managed for TMAO related diseases intervention. Specially, targeting the metaorganismal pathway for TMAO biosynthesis can be achieved by a few key steps, including inhibiting gut microbiota cleavage of TMA containing compounds in nutrient via enzymatic inhibitor, controlling intake of diet rich in TMA precursors and inhibiting the oxidation of TMA to TMAO.

As expected, the injection of antisense oligonucleotide to Ldlr-null mice decreases the hepatic $\mathrm{Fmo3}$ gene expression, resulting in decreased mouse plasma TMAO thereby decreasing aortic lesion in western diet fed mice (Shih et al., 2015). However, the accumulated TMA in mice will show fish odor syndrome. In addition, Fmo3 knockdown exacerbates hepatic endoplasmic reticulum (ER) stress and inflammation (Warrier et al., 2015). Thus, developing gut microbiota enzymatic inhibitors to inhibit TMA formation will be more practical.

A choline analogue, 3,3-dimethylbutanol (DMB), has been uncovered with inhibitory effect to choline TMA lyase activity in turn decreasing circulating TMAO, and therefore attenuating the promoting role of choline in atherosclerosis (Wang et al., 2015). DMB is a natural product, distributed in certain balsamic vinegars, red wines, cold-pressed extra virgin olive oils and grapeseed oils. DMB has not been found any adverse effect to the liver or renal functions even as high as in mice drinking water up to $1 \%$ (Wang et al., 2015). Very recently, we have found that several more choline analogues show more potent in inhibiting choline TMA lyase activity than DMB (to be published). But inhibitors to different enzymatic cleavage of other substrates are still needed. Furthermore, a study shows that resveratrol, a phytoalexin, can decrease plasma TMAO and subsequent atherosclerosis in $\mathrm{ApoE}^{-/-}$mice via gut microbiota remodeling, characterized by increased levels of the genera Lactobacillus and
Bifidobacterium with increased bile salt hydrolase activity to increase bile acid neosynthesis, suggesting the potential of resveratrol as prebiotics (Chen et al., 2016).

\section{UREMIC TOXINS}

Toxins, such as urea and asymmetric dimethylarginine, can be accumulated in blood during chronic kidney disease (CKD), associated to CKD complications especially heart failure which is the leading cause of CKD mortality (Glassock 2008). Moreover, protein-bound uremic toxins such as indoxyl sulfate, indoxyl glucuronide, indoleacetic acid, $p$ cresyl sulfate, $p$-cresyl glucuronide, phenyl sulfate, phenyl glucuronide, phenylacetic acid and hippuric acid have been reported to be increased in serum in hemodialysis patients (Itoh et al., 2013). These uremic toxins are gut microbiota derived metabolites of amino acids (Devlin et al., 2016). The aromatic amino acids in proteins, phenylalanine, tyrosine and tryptophan, can be metabolized by gut microbiota (Nallu et al., 2017; Pereira-Fantini et al., 2017). Both microbiota and host liver are involved in biosynthesis of these uremic toxins (Fig. 3) (Devlin et al., 2016; Meyer and Hostetter 2012; Webster et al., 1976; Gryp et al., 2005).

The serum indoxyl sulfate level, positively correlated with coronary atherosclerosis scores, might be a predicative mechanistic biomarker of coronary artery disease severity (Hsu et al., 2013). Further studies have shown that indoxyl sulfate aggravates cardiac fibrosis, cardiomyocyte hypertrophy and atrial fibrillation (Yisireyili et al., 2013; Aoki et al., 2015). Atrial fibrillation, the most common clinical arrhythmia, results in cardiovascular morbidity and mortality attributed to congestive heart failure and stroke (Hung et al., 2017). Mechanistically, indoxyl sulfate enhances platelet activities, increases response to collagen and thrombin, leading to thrombosis (Yang et al., 2017). Vascular smooth muscle cell calcification is associated with major adverse cardiovascular events while indoxyl sulfate has been found to promote vascular smooth muscle cell calcification (Zhang et al., 2018). Indoxyl sulfate activates NF-kB signaling pathway, leading to increased intercellular adhesion molecule-1 (ICAM-1) and monocyte chemotactic protein-1 (MCP-1) expression in endothelial cells (Tumur et al., 2010). ICAMs over-expression in endothelial cells is the initiating step for atherosclerotic plaque formation (Moss and Ramji 2016). Indoxyl sulfate inhibits nitric oxide production and induces reactive oxygen species production, gradually damaging endothelial cell layer (Tumur and Niwa 2009). Taken together, these studies indicate indoxyl sulfate mechanistically linked to CVD at the molecular and cellular levels.

$p$-Cresyl sulfate is a biomarker in predicting cardiovascular event and renal function progression in CKD patients without dialysis (Lin et al., 2014; Wu et al., 2012). p-Cresyl sulfate can induce NADPH oxidase activity to produce reactive oxygen species, resulting in cardiomyocyte apoptosis and subsequent diastolic dysfunction (Han et al., 2015). Apocynin and $\mathrm{N}$-acetylcysteine, inhibitors to NADPH 


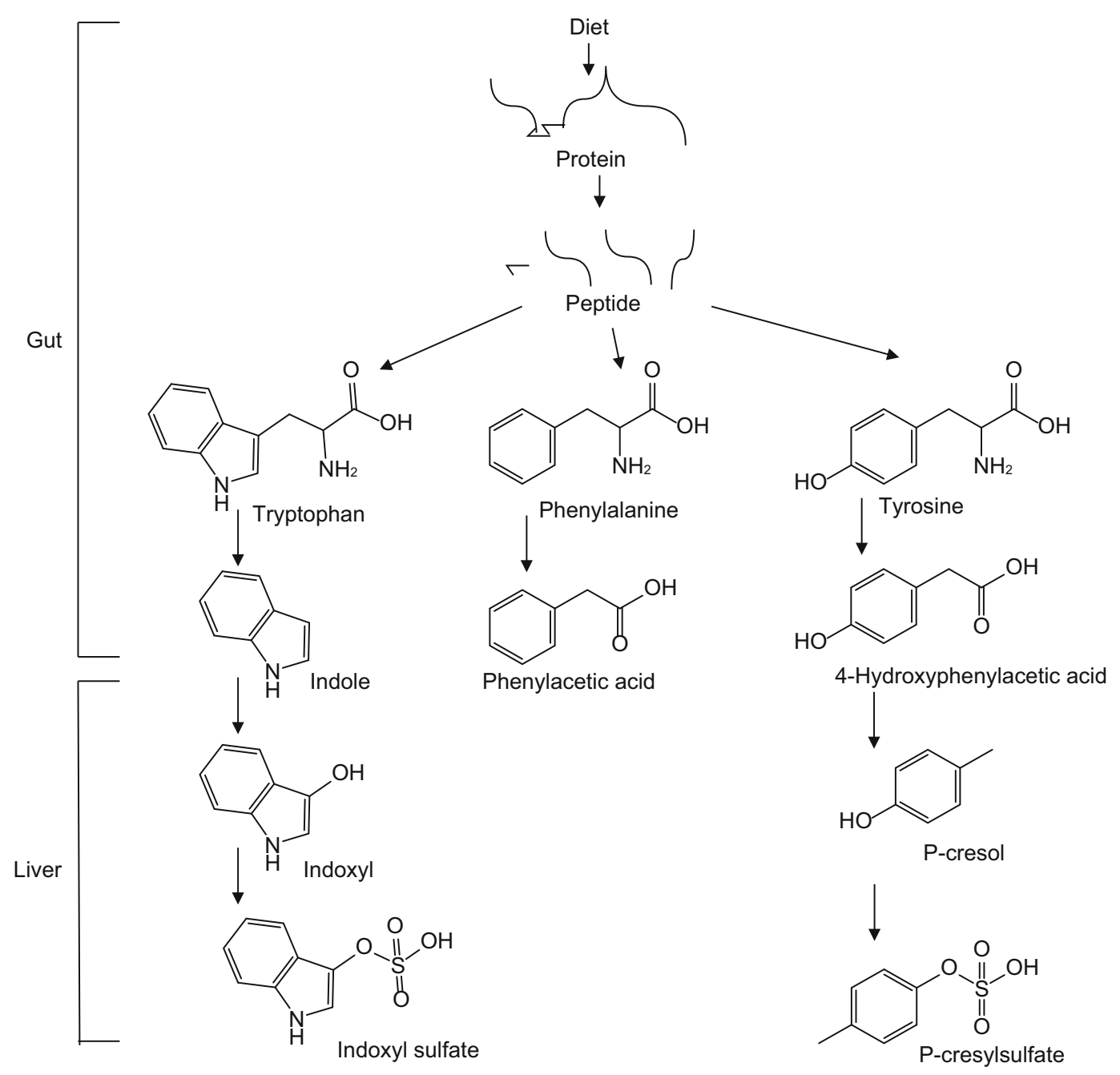

Figure 3. Gut microbiota involved in the biosynthesis of phenylacetic acid, p-cresyl sulfate and indoxyl sulfate.

oxidase, can attenuate the effect of p-cresyl sulfate induced apoptosis (Han et al., 2015). p-Cresyl sulfate increased endothelial cell tumor necrosis factor- $\alpha$ (TNF- $\alpha$ ), MCP-1, ICAM and VCAM expression, therefore mechanistically promotes atherogenesis (Jing et al., 2016). Given that p-cresyl sulfate, very similar to indoxyl sulfate, is notoriously difficult to eliminate by dialysis (Gryp et al., 2005), it is most likely that intervening the biosynthesis pathway is the best way to attenuate such toxic effect.

\section{SHORT CHAIN FATTY ACIDS}

Short chain fatty acids (SCFAs) refer to fatty acids with a carbon number of not greater than 6 , including three major SCFAs, acetic acid, propionic acid, butyric acid, and two less abundant valeric acid and caproic acid. Acetic acid, the most abundant SCFA in the colon with more than half of the total SCFA detected in feces, can be generated by carbohydrate fermentation, or synthesized from hydrogen and carbon dioxide or formic acid through the Wood-Ljungdahl pathway (Miller and Wolin, 1996; Louis et al., 2014). Three distinct pathways including succinate pathway, acrylate pathway, and propanodiol pathway, can generate propionic acid (Reichardt et al., 2014). Butyric acid-producing bacteria use two different pathways, the pathway using phosphotransbutyrylase and butyrate kinase enzymes to convert butyryl-CoA into butyrate (e.g., Coprococcus species) (Louis et al., 2004; Flint et al., 2015), and the butyryl-CoA/acetate CoA-transferase pathway, in which butyryl-CoA is converted to butyric acid in a single step enzymatic reaction (e.g., Faecalibacterium, Eubacterium and Roseburia) (Louis et al., 2010).

The proposed biosynthesis of SCFAs in bacteria is sequential from glycolysis of glucose to pyruvate, to acetyl$\operatorname{coA}$, and eventually to acetic acid, propionic acid and butyric acid. Intriguingly, amino acids are alternative substrate for SCFAs biosynthesis. Glucose and amino acids can be 
digested from starch and protein in small intestine, respectively. Glucose and amino acids can be absorbed into circulating system rapidly prior to reaching colon where microbes accumulated, and the main substrate for the microbes to produce SCFAs is dietary fiber. Both inulin, a kind of fructan, found in many plants, and guar gum are prebiotic fiber (den Besten et al., 2015, 2014; Boets et al., 2015). The beneficial effect of inulin include increasing calcium absorption in colon and decreasing food intake thereafter loss-of-weight (Abrams et al., 2007; Harrold et al., 2013; Liber and Szajewska 2013). Many clinical trials have confirmed a lot of benefits of inulin on health promoting functions and reducing the risk of many diseases, leading to inulin extensively used as nutrient supplement (Kaur and Gupta 2002). Germ free animals have trace amounts of SCFAs, possibly from diet (Hoverstad et al., 1985; Hoverstad and Midtvedt 1986).

Acetic acid producing bacteria are included in Acetobacteraceae containing 10 genera which can oxidize sugars or ethanol to produce acetic acid during fermentation (Raspor and Goranovic 2008). At least 33 strains can produce propionic acid and 225 strains can produce butyric acid by fermenting dietary fiber in human gut (Reichardt et al., 2014; Vital et al., 2014). More interestingly, dietary fiber can selectively increase SCFAs producing bacterium abundance (Zhao et al., 2018).

Short chain fatty acids play important roles in human health. SCFAs can be used to feed colonocyte, maintain gut barrier and inhibit pathogenic microbe proliferation due to acidic pH condition (Hashemi et al., 2017; Cherrington et al., 1991; Prohaszka et al., 1990; Duncan et al., 2009; Manrique Vergara and Gonzalez Sanchez, 2017). SCFAs can work as inhibitors to histone deacetylase (HDAC), which decreases expression of the miR-106b family and increases p21 expression, leading to human colon cancer cell apoptosis (Chen et al., 2003; Hu et al., 2011; Heerdt et al., 1997). SCFAs functions as anticancer therapeutics (Chen et al., 2003). There are three SCFAs receptors expressed in colon epithelial cells including GPR43 (FFAR2), GPR41 (FFAR3) and GPR109A (Karaki et al., 2008; Tazoe et al., 2009; Ahmed et al., 2009). These receptor can trigger secretion of the incretin hormone glucagon-like peptide (GLP)-1 to influence metabolic state and increase peripheral glucose clearance (den Besten et al., 2015; Tolhurst et al., 2012). GPR109A can only be activated by butyric acid, not by acetic acid or propionic acid (Ahmed et al., 2009). Meanwhile, there is another SCFA receptor, OLFR78, expressed in blood vessel and activated by acetic acid and propionic acid but not by butyric acid involved in the modulation of the blood pressure (Pluznick et al., 2013; Pluznick 2014). In addition, recent studies have found a panel of SCFA receptors expressed in distinct cell types, e.g., FFAR2 and FFAR3 in pancreatic $\beta$-cells, FFA3 in neurons, FFA2 in leukocytes, as well as FFA2 and GPR109A in adipocytes, indicating that the ubiquitous and cell-type specific functions of SCFAs (Ahmed et al., 2009; Nilsson et al., 2003). Thus, gut microbiota derived SCFAs actively participate in the host energy hemostasis regulation, play critical regulatory functions in brain, muscle, airway, white adipose tissue, brown adipose tissue and blood vessel physiology (Kasubuchi et al., 2015).

A double-blind randomized placebo-controlled crosssectional study, where eleven normotensive subjects with no family history of essential hypertension were recruited, has found supplementation of miglyol rich in caprylic (8:0) and capric acids (10:0) results in decreased diastolic blood pressure (Maclver et al., 1990). Furthermore, rodent model studies have shown that SCFAs administration can decrease systolic blood pressure mediated by GPR41 expressed in vascular endothelium, while GPR41 knock out mice have isolated systolic hypertension compared with wild-type (WT) mice (Natarajan et al., 2016). Olfr78, a member of the G-protein-coupled receptor family expressed in vascular smooth muscle cells, contributes to blood pressure control as Olfr78-deficient mice showed hypertension (Miyamoto et al., 2016). Therefore, such causality studies including randomized controlled trial and instrumental rodent genetics model, have conclusively shown the pivotal role of SCFAs in blood pressure regulations.

\section{PHYTOESTROGENS}

Phytoestrogens in plant can protect itself from attack by modulation of the fertility of plant predators, vertebrate herbivores (Hughes, 1988). Phytoestrogens are similar to human estrogens in structure. There are three main groups of phytoestrogens, isoflavones, ellagitannins and lignans (Gaya et al., 2108). In the gut, phytoestrogens can be further metabolized to more active molecules, such as equol, $O$ desmethylangolensin (O-DMA), dihydrodaidzein, dihydrogenistein, enterolactone and enterodiol (Fig. 4) (Gaya et al., 2108; Axelson and Setchell 1981; Wang et al., 2005). The biosynthesis pathway of enterolactone and enterodiol have been found from several bacterium strains metabolizing lignan (Vanharanta et al., 2003). Both pinoresinol and lariciresinol, precursors of enterolactone and enterodiol, are a structural moiety in lignin. Lignin is an abundant plantderived polymer secondary to cellulose in amount in the earth (Vanharanta et al., 2003). Lignin can be degraded by gut microbiota to release lignans (DeAngelis et al., 2011). Equol and O-DMA can be metabolized from daidzein in the gut by several bacterium strains, such as Adlercreutzia equolifaciens, Eggerthella sp. YY7918, Lactococcus garvieae, Slackia equolifaciens, Slackia isoflavoniconvertens, Slackia sp. NATTS (Braune and Blaut, 2018; Guadamuro et al., 2017; Matthies et al., 2012; Frankenfeld et al., 2014).

Phytoestrogens are reported to reduce breast cancer for postmenopausal women (Goodman et al., 2009). In animal model, pretreatment of phytoestrogen-rich, Pueraria mirifica tuberous powder resulted in decreasing the virulence of rat breast tumor development induced by 7,12-dimethylbenz(a) anthracene (Cherdshewasart et al., 2007). Besides breast cancer, phytoestrogens may have protective action against 


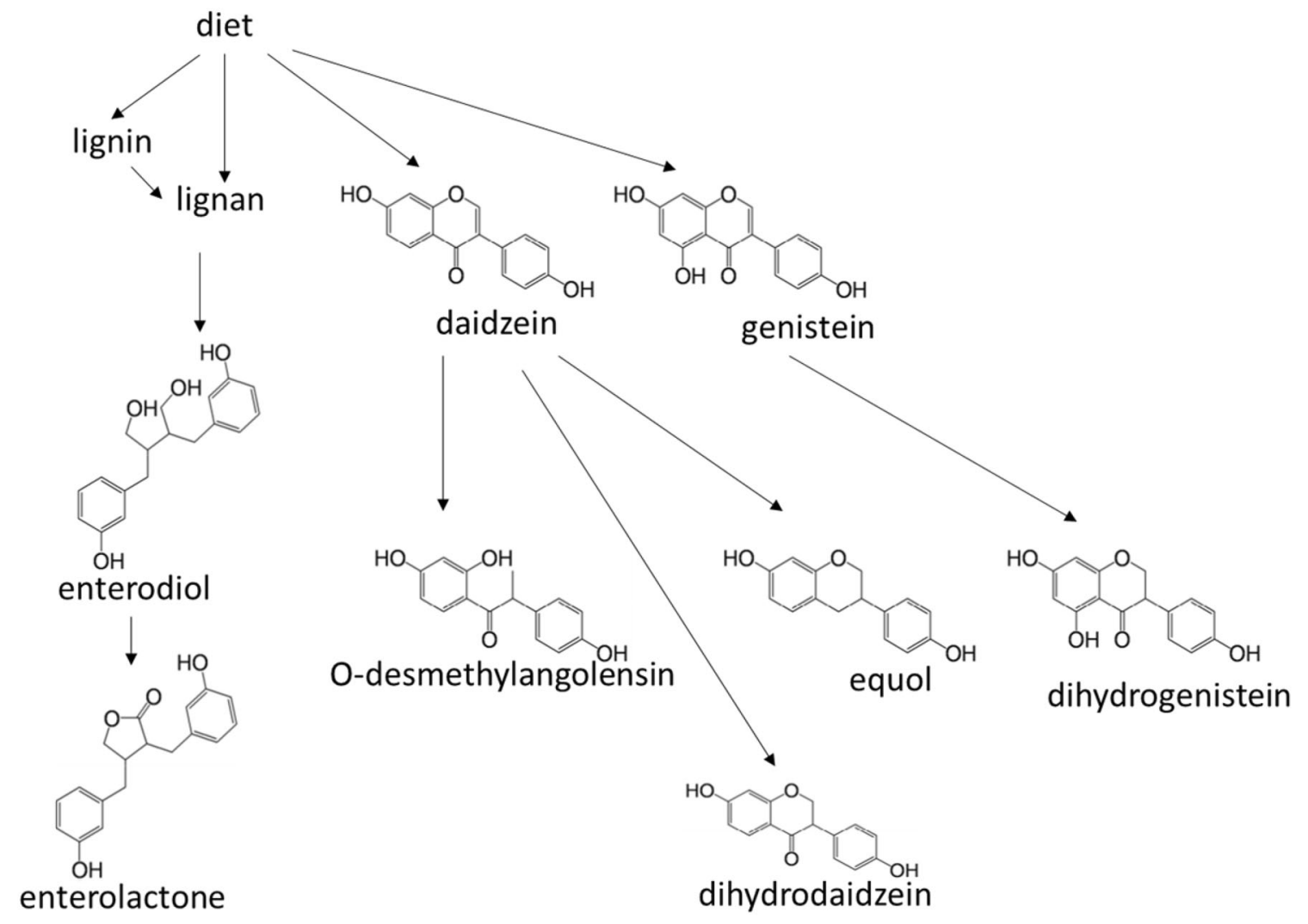

Figure 4. Structural formulas of phytoesterogens and the metabolism pathways.

prostate, bowel and other cancers, cardiovascular disease, brain function disorders and osteoporosis (Zhang et al., 2016; Ward and Kuhnle 2010; Arbabi et al., 2016; Menze et al., 2015; Trieu and Uckun 1999; Chiechi et al., 1999; Wang et al., 2011; Zhang et al., 2004; Lephart et al., 2001). However, a few investigations implicate that the controversial role of phytoestrogens including increasing colorectal cancer and prostate cancer risk and indicate little supportive evidence of phytoestrogens decreasing cardiovascular disease risk (Ward et al., 2010; van der Schouw et al., 2005; Peterson et al., 2010).

Enterolactone is a biphenol, which can function as antioxidant. A study shows that high serum enterolactone level is associated with reduced CVD mortality (Vanharanta et al., 2003). Furthermore, low serum enterolactone is associated with increased in vivo lipid peroxidation, assessed by plasma F2-isoprostane concentrations (Vanharanta et al., 2002). In addition, urinary total and individual phytoestrogens were significantly inversely associated with serum C-reactive protein (CRP; an inflammation biomarker) (Reger et al., 2017). Phytoestrogens can bind to estrogen receptors (Morito et al., 2001), which either mimics estrogen or works as antagonist (Fitzpatrick, 1999). Thus, the effects of phytoestrogens can be biphasic: for example, phytoestrogens both increases vasodilation and nitric oxide metabolism that may have a favorable impact on vascular health; on the other hand, phytoestrogen may also have some prothrombotic or proinflammatory effects that may offset other benefits (Herrington, 2000). Both enterolactone and enterodiol can alleviate the effect of peripheral blood lymphocytes activated by lipopolysaccharide (Corsini et al., 2010). Such lymphocytes activation leads to inhibitory-KB (I-KB) degradation and nuclear factor-kB (NF-kB) activation thereby resulting in TNF- $\alpha$ production (Corsini et al., 2010). Thus, both enterolactone and enterodiol may have pro-anti-inflammatory role.

\section{ANTHOCYANINS}

Anthocyanins are glycosyl-anthocyanidins, widely distributed in plant vacuole with $\mathrm{pH}$ depending color. Anthocyanidins are flavones with different functional groups covalently linked to the three cycles. Anthocyanins have been found with beneficial effects on obesity and diabetes control, cardiovascular disease and cancer prevention, and visual and brain function improvement (Tsuda, 2012; Hannum, 2004). Mechanistically, the beneficial effect of anthocyanins on cardiovascular health include working as an antiplatelet agent in atherosclerosis and other CVD prevention, inducing nitric oxide formation in vessel thereby 


$$
\text { diet }
$$

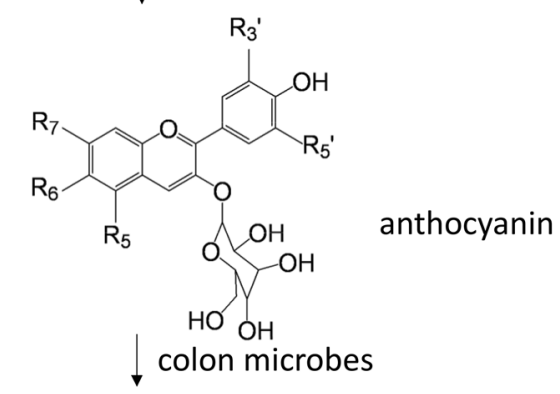<smiles></smiles>
anthocyanidin<smiles>O=C(O)c1ccc(O)c(O)c1</smiles>

protocatechuic acid

Figure 5. Colon microbes contribute to protocatechuic acid biosynthesis from diet anthocyanins. $\mathrm{R}_{3}{ }^{\prime}=\mathrm{H}, \mathrm{OH}$ or $\mathrm{OCH}_{3}$; $\mathrm{R}_{5}{ }^{\prime}=\mathrm{H}, \mathrm{OH}$ or $\mathrm{OCH}_{3} ; \mathrm{R}_{5}=\mathrm{OH}$ or $\mathrm{OCH}_{3} ; \mathrm{R}_{6}=\mathrm{H}$ or $\mathrm{OH} ; \mathrm{R}_{7}=\mathrm{OH}$ or $\mathrm{OCH}_{3} . \mathrm{R}_{5}, \mathrm{R}_{7}$ can be glycosylated if it is a hydroxyl group.

enhancing vasorelaxation, protecting cardiac cells from oxidative-stress-induced apoptosis, and increasing HDL cholesterol as well (Gaiz et al., 2018; Stoclet et al., 1999; Hassellund et al., 2013; Isaak et al., 2017).

Further investigations have confirmed that the beneficial effect of some anthocyanins on atherosclerosis is mediated by gut microbiota metabolites. Ingested dietary anthocyanins are absorbed with a small part while large amounts are likely to enter the colon to be degraded by gut microbiota as free anthocyanidins and protocatechuic acid (PCA) (Fig. 5) (Aura et al., 2005). Anthocyanidin-3-glucoside promotes reverse cholesterol transport mediated by its gut microbiota metabolite, PCA. PCA can reduce macrophage miR-10b expression, therefore increasing $A B C A 1$ and $A B C G 1$ expression (Wang et al., 2012). Gallic acid (GA), one of the microbiota anthocyanin metabolites, has been shown increasing nitric oxide (NO) levels by increasing phosphorylation of endothelial nitric oxide synthase (eNOS) (Radtke et al., 2004). GA inhibited angiotensin-I converting enzyme (ACE), leading to reduced blood pressure in spontaneously hypertensive rats (SHR) comparable to captopril (Kang et al., 2015). These results suggest that GA isolated from Spirogyra sp. exerts multiple therapeutic effects and has a great potential for CVD intervention.
Anthocyanins can also modulate gut microbiota community structure. For example, malvidin-3-glucoside can enhance the growth of some beneficial bacterium such as Bifidobaterium spp. and Lactobacillus spp. (Hidalgo et al., 2012). On the other hand, gallic acid, one of the microbiota anthocyanin metabolites, can reduce some potentially harmful bacteria such as Clostridium histolyticum, without negative effect on beneficial bacteria (Hidalgo et al., 2012). Study on comparison in gut microbiota fingerprints between cardiovascular disease patients and healthy controls has shown that the diversity of beneficial bacteria was reduced in patients with cardiovascular disease (Vamanu et al., 2016). Thus, anthocyanins play critical role in shaping the microbiota taxonomic composition especially under CVD conditions.

\section{BILE ACIDS}

Bile acids are synthesized from cholesterol in liver. The initial products are chenodeoxycholic acid (CDCA) and cholic acid (CA) (Fig. 6), and then conjugated with glycine or taurine, stored and concentrated in gallbladder (Wahlstrom et al., 2016; LaRusso et al., 1974). Bile acids produced in liver are called as primary bile acids. Bile acids are released into duodenum after meal to emulsify dietary fats and oils for digestion and help absorb lipid soluble vitamins (Danielsson, 1963; Hollander et al., 1977; Barnard and Heaton, 1973; Miettinen, 1971). In ileum, conjugated bile acids are then reabsorbed and carried in the portal blood to liver. This process is called enterohepatic circulation and preserves more than $95 \%$ of the bile acid pool (Wahlstrom et al., 2016). In distal ileum, conjugated bile acids are hydrolyzed to remove glycine or taurine by bile salt hydrolase in microbes to escape reuptake by apical sodium dependent bile acid transporter and dehydroxylated by microbes as deoxycholic acid or lithocholic acid, which are called as secondary bile acids (Fig. 6), (Wahlstrom et al., 2016; Chiang, 2009). The deconjugated bile acids are hydrophobic and it can be excreted as feces, which constitutes the last step of reverse cholesterol efflux to decrease circulating cholesterol (Dawson and Karpen, 2015), therefore the risk for atherosclerosis can be decreased.

Bile acid can modulate gut microbiota composition by killing bacterium in a species and dosage dependent way (Yokota et al., 2012). Bile acids are associated with metabolic disease, obesity, diarrhea, inflammatory bowel disease, colorectal cancer and hepatocellular carcinoma as well (Joyce and Gahan, 2016).

Bile acids can work as hormone to act on farnesoid $X$ receptor (FXR) and $G$ protein-coupled membrane receptor 5 (TGR5) to decrease triglyceride accumulation, fatty acid oxidation, decrease the expression of pro-inflammatory cytokines and chemokines in aorta through the inactivation of NF-KB (Levi, 2016; Porez et al., 2012).

Gut microbiota can affect cardiovascular health via secondary bile acids, deoxycholic acid and lithocholic acid, both 


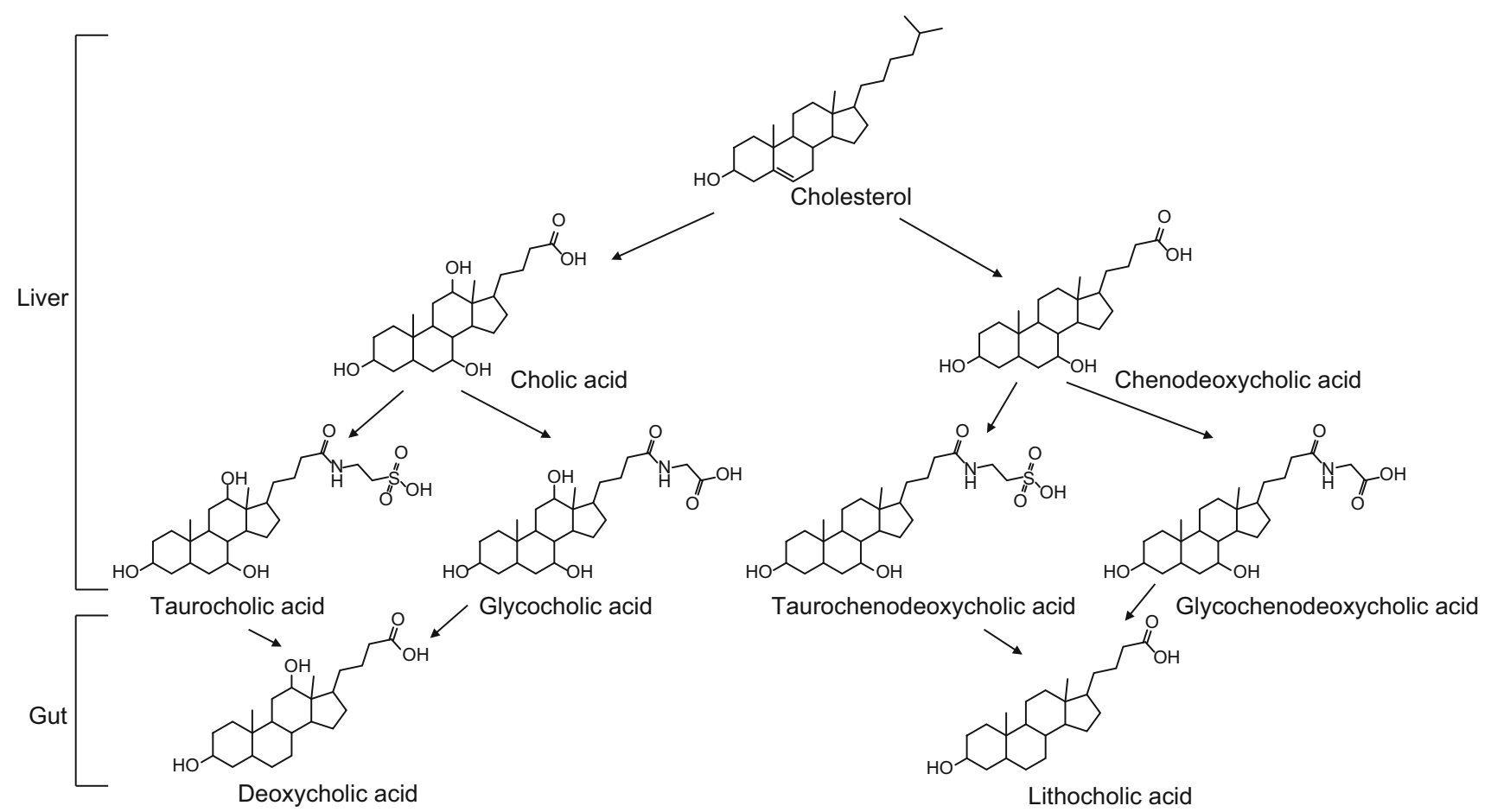

Figure 6. The main bile acids and their metabolic pathways.

of which are the main ligand for TGR5 (Fiorucci et al., 2010; Duboc et al., 2014). Primary bile acids including chenodeoxycholic acid and cholic acid, with FXR as their the receptor, have distinct effects on cardiac health when compared to secondary bile acids (Fiorucci et al., 2010). Consistently, the serum level of primary bile acids were found decreased while ratios of secondary bile acids to primary bile acids were increased in cardiovascular disease patients compared to healthy controls (Mayerhofer et al., 2017).

\section{LIPOPOLYSACCHARIDE}

Distinguished from the abovementioned gut microbiota derived metabolites, lipopolysaccharide (LPS, also called as endotoxin) is a component of outer-membrane of Gramnegative bacteria with a very complicated structural formula composed of lipid and saccharide. LPS is released from the bacterial membrane after destruction with the capacity of inducing systemic inflammation and sepsis (Beutler and Rietschel, 2003). For healthy subjects, gut-blood barrier prevents LPS entering circulating blood. However, the gutblood barrier leak due to dysbiosis results in bacterium entering the bloodstream. For the periodontal patients, bacterium can directly enter circulating blood, leading to increased levels of circulating LPS (Fukui et al., 1991; Wang et al., 2015; de Punder and Pruimboom, 2015; Lakio et al., 2006).
LPS can induce foam cell formation and cholesteryl ester accumulation from native low density lipoprotein, indicating LPS is proatherogenic (Lakio et al., 2006; Funk et al., 1993). LPS induces CD14 and SR-Al expression in macrophages via JNK1, leading to oxLDL uptake and foam cell formation (An et al., 2017). LPS binding protein (LBP) is synthesized in liver and released to circulating blood (Schumann et al., 1990). Serum LBP level in patients with angiographically confirmed coronary artery disease (CAD) found significantly higher than controls without CAD is an independent predictive biomarker for total and cardiovascular mortality (Lepper et al., 2011). Moreover, the high affinity binding complex of LPS-LBP binds to monocyte and macrophage, triggering the secretion of tumor necrosis factor (Schumann et al., 1990). Toll-like receptor 4 (TLR4) is the membrane receptor of LPS, when activated, triggering NF-KB signaling and producing proinflammatory cytokines (Lu et al., 2008). Further, inflammatory caspase- $4,-5$ and -11 directly recognize bacterial LPS, both of which trigger pyroptosis (Shi et al., 2015). Low serum selenium or selenoprotein P (SePP) levels have been repetitively observed in severe sepsis, and both purified SePP and synthetic peptides corresponding to the Hisrich motifs neutralized LPS (Zhao et al., 2016). Very recently, a study shows itaconate is required for the activation of the anti-inflammatory transcription factor Nrf2 (also known as NFE2L2) by lipopolysaccharide in mouse and human 
macrophages via dicarboxylation of KEAP1 (Mills et al., 2018). Taken together, LPS is a mechanistic biomarker for CAD.

\section{PROSPECT}

More and more gut microbiota derived metabolites have been unveiled as crucial factor contributing to cardiovascular health and disease. Thus, a better understanding of the gut microbe pathways involved in the biosynthesis of CVD related metabolites would greatly facilitate managing cardiac health especially preventing CVD.

Apparently, for mechanistic biomarker discovery and CVD management, it is of primary importance to pinpoint the causal role of gut microbiota derived metabolites. Koch's postulate, which states that a given pathogen leads to a distinct disease, have been evolving into molecular and ecological Koch's postulate including CVD (Vonaesch et al., 2018). Therefore, many ongoing efforts have been focusing on the causality of gut microbiota derived metabolites in CVD. Key methodologies include randomized controlled trials (Tang et al., 2013; Panigrahi et al., 2017), Mendelian randomization approach (Mendelson et al., 2017) and gnotobiotic animal models (Hibberd et al., 2017).

Given that diet is the most important factor shaping the dynamics of gut microbiotia (Rothschild et al., 2018), integrative studies on diet shaped microbiota-host interactions have the potential to offer us novel insight on CVD mechanisms. From the microbiota side, there is big room to study molecular genetics mechanisms by which how the physiology and pathology relevant microbiota taxonomic and functional profiles are regulated. Of note, studies on the immune mechanisms of CVD allow us to connect gut microbiota derived metabolites to key immune components of distinct immune cell and cytokine profile dynamics. We envision discovering predicative mechanistic CVD microbiome biomarkers and exploiting the probiotics and prebiotics therapeutics continue to be of primary priority.

\section{ACKNOWLEDGEMENTS}

Z. Wang is supported by grants from the National Institutes of Health and the Office of Dietary Supplements (R01HL130819).

\section{ABBREVIATIONS}

ACE, angiotensin-I converting enzyme; CA, cholic acid; CDCA, chenodeoxycholic acid; CKD, chronic kidney disease; cntA/B, carnitine monooxygenase; cutC/D, choline-TMA lyase; CVD, cardiovascular disease; DMB, 3,3-dimethylbutanol; eNOS, endothelial nitric oxide synthase; ER, endoplasmic reticulum; FMOs, flavin monooxygenase; GA, gallic acid; IBD, inflammatory bowel disease; ICAM-1, intercellular adhesion molecule-1; I-KB, inhibitory-KB; LPS, lipopolysaccharide; MCP-1, monocyte chemotactic protein-1; NF$\mathrm{kB}$, nuclear factor-kB; NO, nitric oxide; O-DMA, O-desmethylangolensin; PCA, protocatechuic acid; SCFAs, short chain fatty acids; SHR, spontaneously hypertensive rats; TLR4, Toll-like receptor 4;
TMA, trimethylamine; TMAO, trimethylamine- $N$-oxide; TNF- $\alpha$, tumor necrosis factor- $\alpha$.

\section{COMPLIANCE WITH ETHICS GUIDELINES}

Zeneng Wang is named as co-inventor on pending and issued patents held by the Cleveland Clinic relating to cardiovascular diagnostics and therapeutics, and has the right to receive royalty payment for inventions or discoveries related to cardiovascular diagnostics or therapeutics from Cleveland Heart Lab or Proctor \& Gamble. Yongzhong Zhao declares that he has no conflict of interest. This article does not contain any studies with human or animal subjects performed by the any of the authors.

\section{OPEN ACCESS}

This article is distributed under the terms of the Creative Commons Attribution 4.0 International License (http://creativecommons.org/ licenses/by/4.0/), which permits unrestricted use, distribution, and reproduction in any medium, provided you give appropriate credit to the original author(s) and the source, provide a link to the Creative Commons license, and indicate if changes were made.

\section{REFERENCES}

Abrams SA et al (2007) An inulin-type fructan enhances calcium absorption primarily via an effect on colonic absorption in humans. J Nutr 137:2208-2212

Ahmed K, Tunaru S, Offermanns S (2009) GPR109A, GPR109B and GPR81, a family of hydroxy-carboxylic acid receptors. Trends Pharmacol Sci 30:557-562. https://doi.org/10.1016/j. tips.2009.09.001

An D et al (2017) JNK1 mediates lipopolysaccharide-induced CD14 and SR-Al expression and macrophage foam cell formation. Front Physiol 8:1075. https://doi.org/10.3389/fphys.2017.01075

Andreesen JR (1994) Glycine metabolism in anaerobes. Antonie Van Leeuwenhoek 66:223-237

Anhe FF et al (2015) Gut microbiota dysbiosis in obesity-linked metabolic diseases and prebiotic potential of polyphenol-rich extracts. Curr Obes Rep 4:389-400. https://doi.org/10.1007/ s13679-015-0172-9

Aoki K et al (2015) Role of indoxyl sulfate as a predisposing factor for atrial fibrillation in renal dysfunction. J Am Heart Assoc 4: e002023. https://doi.org/10.1161/JAHA.115.002023

Arbabi E, Hamidi G, Talaei SA, Salami M (2016) Estrogen agonist genistein differentially influences the cognitive and motor disorders in an ovariectomized animal model of Parkinsonism. Iran J Basic Med Sci 19:1285-1290. https://doi.org/10.22038/ijbms. 2016.7911

Aura AM et al (2005) In vitro metabolism of anthocyanins by human gut microflora. Eur J Nutr 44:133-142. https://doi.org/10.1007/ s00394-004-0502-2

Axelson M, Setchell KD (1981) The excretion of lignans in ratsevidence for an intestinal bacterial source for this new group of compounds. FEBS Lett 123:337-342 
Bakken JS, Polgreen PM, Beekmann SE, Riedo FX, Streit JA (2013) Treatment approaches including fecal microbiota transplantation for recurrent Clostridium difficile infection (RCDI) among infectious disease physicians. Anaerobe 24:20-24. https://doi.org/10. 1016/j.anaerobe.2013.08.007

Barnard DL, Heaton KW (1973) Bile acids and vitamin A absorption in man: the effects of two bile acid-binding agents, cholestyramine and lignin. Gut 14:316-318

Battson ML et al (2017) Suppression of gut dysbiosis reverses western diet-induced vascular dysfunction. Am J Physiol Endocrinol Metab. https://doi.org/10.1152/ajpendo.00187.2017

Bennett BJ et al (2013) Trimethylamine- $N$-oxide, a metabolite associated with atherosclerosis, exhibits complex genetic and dietary regulation. Cell Metab 17:49-60. https://doi.org/10.1016/j. cmet.2012.12.011

Beutler B, Rietschel ET (2003) Innate immune sensing and its roots: the story of endotoxin. Nat Rev Immunol 3:169-176. https://doi. org/10.1038/nri1004

Bhattarai Y, Kashyap PC (2016) Germ-free mice model for studying host-microbial interactions. Methods Mol Biol 1438:123-135. https://doi.org/10.1007/978-1-4939-3661-8_8

Bodea S, Funk MA, Balskus EP, Drennan CL (2016) Molecular basis of $\mathrm{C}-\mathrm{N}$ bond cleavage by the glycyl radical enzyme choline trimethylamine-lyase. Cell Chem Biol 23:1206-1216. https://doi. org/10.1016/j.chembiol.2016.07.020

Boets E et al (2015) Quantification of in vivo colonic short chain fatty acid production from inulin. Nutrients 7:8916-8929. https://doi. org/10.3390/nu7115440

Boini KM, Hussain T, Li PL, Koka S (2017) Trimethylamine- $N$-oxide instigates NLRP3 inflammasome activation and endothelial dysfunction. Cell Physiol Biochem 44:152-162. https://doi.org/ 10.1159/000484623

Braune A, Blaut M (2018) Evaluation of inter-individual differences in gut bacterial isoflavone bioactivation in humans by PCR-based targeting of genes involved in equol formation. J Appl Microbiol 124:220-231. https://doi.org/10.1111/jam.13616

Chen JS, Faller DV, Spanjaard RA (2003) Short-chain fatty acid inhibitors of histone deacetylases: promising anticancer therapeutics? Curr Cancer Drug Targ 3:219-236

Chen ML et al (2016) Resveratrol attenuates trimethylamine- $N$-oxide (TMAO)-induced atherosclerosis by regulating TMAO synthesis and bile acid metabolism via remodeling of the gut microbiota. MBio 7:e02210-e02215. https://doi.org/10.1128/mBio.02210-15

Chen $\mathrm{ML}$ et al (2017) Trimethylamine- $\mathrm{N}$-oxide induces vascular inflammation by activating the NLRP3 inflammasome through the SIRT3-SOD2-mtROS signaling pathway. J Am Heart Assoc. https://doi.org/10.1161/jaha.117.006347

Cherdshewasart W, Panriansaen R, Picha P (2007) Pretreatment with phytoestrogen-rich plant decreases breast tumor incidence and exhibits lower profile of mammary ERalpha and ERbeta. Maturitas 58:174-181. https://doi.org/10.1016/j.maturitas.2007. 08.001

Cherrington CA, Hinton M, Pearson GR, Chopra I (1991) Short-chain organic acids at ph 5.0 kill Escherichia coli and Salmonella spp. without causing membrane perturbation. J Appl Bacteriol 70:161165
Chiang JY (2009) Bile acids: regulation of synthesis. J Lipid Res 50:1955-1966. https://doi.org/10.1194/jlr.R900010-JLR200

Chiechi LM, Lobascio A, Grillo A, Valerio T (1999) Phytoestrogencontaining food and prevention of postmenopausal osteoporosis and cardiovascular diseases. Minerva Ginecol 51:343-348

Corsini E et al (2010) Enterodiol and enterolactone modulate the immune response by acting on nuclear factor-kappaB (NFkappaB) signaling. J Agric Food Chem 58:6678-6684. https://doi. org/10.1021/jf100471n

Craciun S, Marks JA, Balskus EP (2014) Characterization of choline trimethylamine-lyase expands the chemistry of glycyl radical enzymes. ACS Chem Biol 9:1408-1413. https://doi.org/10.1021/ cb500113p

Danielsson H (1963) Influence of bile acids on digestion and absorption of lipids. Am J Clin Nutr 12:214-219

Dawson PA, Karpen SJ (2015) Intestinal transport and metabolism of bile acids. J Lipid Res 56:1085-1099. https://doi.org/10.1194/ jlr.R054114

de Punder K, Pruimboom L (2015) Stress induces endotoxemia and low-grade inflammation by increasing barrier permeability. Front Immunol 6:223. https://doi.org/10.3389/fimmu.2015.00223

DeAngelis KM et al (2011) Characterization of trapped lignindegrading microbes in tropical forest soil. PLoS ONE 6:e19306. https://doi.org/10.1371/journal.pone.0019306

DeGruttola AK, Low D, Mizoguchi A, Mizoguchi E (2016) Current understanding of dysbiosis in disease in human and animal models. Inflamm Bowel Dis 22:1137-1150. https://doi.org/10. 1097/MIB.0000000000000750

Delgado S, Leite AM, Ruas-Madiedo P, Mayo B (2014) Probiotic and technological properties of Lactobacillus spp. strains from the human stomach in the search for potential candidates against gastric microbial dysbiosis. Front Microbiol. https://doi.org/10. 3389/fmicb.2014.00766

den Besten $\mathrm{G}$ et al (2014) The short-chain fatty acid uptake fluxes by mice on a guar gum supplemented diet associate with amelioration of major biomarkers of the metabolic syndrome. PLoS ONE 9:e107392. https://doi.org/10.1371/journal.pone.0107392

den Besten $G$ et al (2015) Protection against the metabolic syndrome by guar gum-derived short-chain fatty acids depends on peroxisome proliferator-activated receptor gamma and glucagon-like peptide-1. PLoS ONE 10:e0136364. https://doi.org/10. 1371/journal.pone.0136364

Devlin AS et al (2016) Modulation of a circulating uremic solute via rational genetic manipulation of the gut microbiota. Cell Host Microbe 20:709-715. https://doi.org/10.1016/j.chom.2016.10.021

Dolphin CT, Riley JH, Smith RL, Shephard EA, Phillips IR (1997) Structural organization of the human flavin-containing monooxygenase 3 gene (FMO3), the favored candidate for fish-odor syndrome, determined directly from genomic DNA. Genomics 46:260-267. https://doi.org/10.1006/geno.1997.5031

Duboc H, Tache Y, Hofmann AF (2014) The bile acid TGR5 membrane receptor: from basic research to clinical application. Dig Liver Dis 46:302-312. https://doi.org/10.1016/j.dld.2013.10. 021

Duncan SH, Louis P, Thomson JM, Flint HJ (2009) The role of $\mathrm{pH}$ in determining the species composition of the human colonic 
microbiota. Environ Microbiol 11:2112-2122. https://doi.org/10. 1111/j.1462-2920.2009.01931.x

Fan $\mathrm{P}$ et al (2015) Metabolites of dietary protein and peptides by intestinal microbes and their impacts on gut. Curr Protein Pept Sci 16:646-654

Fiorucci S, Cipriani S, Baldelli F, Mencarelli A (2010) Bile acidactivated receptors in the treatment of dyslipidemia and related disorders. Prog Lipid Res 49:171-185. https://doi.org/10.1016/j. plipres.2009.11.001

Fitzpatrick LA (1999) Selective estrogen receptor modulators and phytoestrogens: new therapies for the postmenopausal women. Mayo Clin Proc 74:601-607

Flint HJ, Duncan SH, Scott KP, Louis P (2015) Links between diet, gut microbiota composition and gut metabolism. Proc Nutr Soc 74:13-22. https://doi.org/10.1017/S0029665114001463

Frankenfeld CL, Atkinson C, Wahala K, Lampe JW (2014) Obesity prevalence in relation to gut microbial environments capable of producing equol or O-desmethylangolensin from the isoflavone daidzein. Eur J Clin Nutr 68:526-530. https://doi.org/10.1038/ ejcn.2014.23

Fukui H, Brauner B, Bode JC, Bode C (1991) Plasma endotoxin concentrations in patients with alcoholic and non-alcoholic liver disease: reevaluation with an improved chromogenic assay. J Hepatol 12:162-169

Funk JL, Feingold KR, Moser AH, Grunfeld C (1993) Lipopolysaccharide stimulation of RAW 264.7 macrophages induces lipid accumulation and foam cell formation. Atherosclerosis 98:67-82

Gaiz AA, Mosawy S, Colson N, Singh I (2018) Potential of anthocyanin to prevent cardiovascular disease in diabetes. Altern Ther Health Med

Gaya P, Medina M, Sanchez-Jimenez A, Landete JM (2016) Phytoestrogen metabolism by adult human gut microbiota. Molecules. https://doi.org/10.3390/molecules21081034

Glassock RJ (2008) Uremic toxins: what are they? An integrated overview of pathobiology and classification. J Ren Nutr 18:2-6. https://doi.org/10.1053/j.jrn.2007.10.003

Gonzaga-Jauregui C, Lupski JR, Gibbs RA (2012) Human genome sequencing in health and disease. Annu Rev Med 63:35-61. https://doi.org/10.1146/annurev-med-051010-162644

Goodman MT et al (2009) Urinary phytoestrogen excretion and postmenopausal breast cancer risk: the multiethnic cohort study. Cancer Prev Res (Phila) 2:887-894. https://doi.org/10.1158/ 1940-6207.CAPR-09-0039

Gregory JC et al (2015) Transmission of atherosclerosis susceptibility with gut microbial transplantation. J Biol Chem 290:56475660. https://doi.org/10.1074/jbc.M114.618249

Gryp T, Vanholder R, Vaneechoutte M, Glorieux G (2017) p-Cresyl sulfate. Toxins (Basel). https://doi.org/10.3390/toxins9020052

Guadamuro L, Dohrmann AB, Tebbe CC, Mayo B, Delgado S (2017) Bacterial communities and metabolic activity of faecal cultures from equol producer and non-producer menopausal women under treatment with soy isoflavones. BMC Microbiol 17:93. https://doi.org/10.1186/s12866-017-1001-y

Hamilton MK et al (2017) Prebiotic milk oligosaccharides prevent development of obese phenotype, impairment of gut permeability, and microbial dysbiosis in high fat-fed mice. Am J Physiol
Gastrointest Liver Physiol 312:G474-G487. https://doi.org/10. 1152/ajpgi.00427.2016

Han $\mathrm{H}$ et al (2015) p-Cresyl sulfate aggravates cardiac dysfunction associated with chronic kidney disease by enhancing apoptosis of cardiomyocytes. J Am Heart Assoc 4:e001852. https://doi.org/ 10.1161/JAHA. 115.001852

Hannum SM (2004) Potential impact of strawberries on human health: a review of the science. Crit Rev Food Sci Nutr 44:1-17. https://doi.org/10.1080/10408690490263756

Harrold JA et al (2013) Acute effects of a herb extract formulation and inulin fibre on appetite, energy intake and food choice. Appetite 62:84-90. https://doi.org/10.1016/j.appet.2012.11.018

Hashemi Z, Fouhse J, Im HS, Chan CB, Willing BP (2017) Dietary pea fiber supplementation improves glycemia and induces changes in the composition of gut microbiota, serum short-chain fatty acid profile and expression of mucins in glucose intolerant rats. Nutrient. https://doi.org/10.3390/nu9111236

Hassellund SS et al (2013) Effects of anthocyanins on cardiovascular risk factors and inflammation in pre-hypertensive men: a double-blind randomized placebo-controlled crossover study. J Hum Hypertens 27:100-106. https://doi.org/10.1038/jhh.2012.4

Heerdt BG, Houston MA, Augenlicht LH (1997) Short-chain fatty acid-initiated cell cycle arrest and apoptosis of colonic epithelial cells is linked to mitochondrial function. Cell Growth Differ 8:523532

Herrington D (2000) Role of estrogens, selective estrogen receptor modulators and phytoestrogens in cardiovascular protection. Can J Cardiol 16(Suppl E):5E-9E

Hibberd MC et al (2017) The effects of micronutrient deficiencies on bacterial species from the human gut microbiota. Sci Transl Med. https://doi.org/10.1126/scitranslmed.aal4069

Hidalgo $\mathrm{M}$ et al (2012) Metabolism of anthocyanins by human gut microflora and their influence on gut bacterial growth. J Agric Food Chem 60:3882-3890. https://doi.org/10.1021/jf3002153

Hollander D, Rim E, Ruble PE Jr (1977) Vitamin K2 colonic and ileal in vivo absorption: bile, fatty acids, and $\mathrm{pH}$ effects on transport. Am J Physiol 233:E124-E129. https://doi.org/10.1152/ajpendo. 1977.233.2.E124

Hoverstad T, Midtvedt T (1986) Short-chain fatty acids in germfree mice and rats. J Nutr 116:1772-1776

Hoverstad T, Midtvedt T, Bohmer T (1985) Short-chain fatty acids in intestinal content of germfree mice monocontaminated with Escherichia coli or Clostridium difficile. Scand J Gastroenterol 20:373-380

Hsu CC et al (2013) Levels of indoxyl sulfate are associated with severity of coronary atherosclerosis. Clin Invest Med 36:E42-E49

Hu S et al (2011) The microbe-derived short chain fatty acid butyrate targets miRNA-dependent p21 gene expression in human colon cancer. PLoS ONE 6:e16221. https://doi.org/10.1371/journal. pone.0016221

Hughes CL Jr (1988) Phytochemical mimicry of reproductive hormones and modulation of herbivore fertility by phytoestrogens. Environ Health Perspect 78:171-174

Hung SC, Kuo KL, Wu CC, Tarng DC (2017) Indoxyl sulfate: a novel cardiovascular risk factor in chronic kidney disease. J Am Heart Assoc. https://doi.org/10.1161/jaha.116.005022 
Isaak CK, Petkau JC, Blewett H, Karmin O, Siow YL (2017) Lingonberry anthocyanins protect cardiac cells from oxidativestress-induced apoptosis. Can J Physiol Pharmacol 95:904-910. https://doi.org/10.1139/cjpp-2016-0667

Itoh Y, Ezawa A, Kikuchi K, Tsuruta Y, Niwa T (2013) Correlation between serum levels of protein-bound uremic toxins in hemodialysis patients measured by LC/MS/MS. Mass Spectrom (Tokyo) 2:S0017. https://doi.org/10.5702/massspectrometry. s0017

Jing YJ et al (2016) p-Cresyl sulfate is associated with carotid arteriosclerosis in hemodialysis patients and promotes atherogenesis in apoE-/-mice. Kidney Int 89:439-449. https://doi.org/10. 1038/ki.2015.287

Joyce SA, Gahan CG (2016) Bile acid modifications at the microbehost interface: potential for nutraceutical and pharmaceutical interventions in host health. Annu Rev Food Sci Technol 7:313333. https://doi.org/10.1146/annurev-food-041715-033159

Kalnins $\mathrm{G}$ et al (2015) Structure and function of CutC choline lyase from human microbiota bacterium Klebsiella pneumoniae. J Biol Chem 290:21732-21740. https://doi.org/10.1074/jbc.M115. 670471

Kang N et al (2015) Gallic acid isolated from Spirogyra sp. improves cardiovascular disease through a vasorelaxant and antihypertensive effect. Environ Toxicol Pharmacol 39:764-772. https:// doi.org/10.1016/j.etap.2015.02.006

Karaki $S$ et al (2008) Expression of the short-chain fatty acid receptor, GPR43, in the human colon. J Mol Histol 39:135-142. https://doi.org/10.1007/s10735-007-9145-y

Kasubuchi M, Hasegawa S, Hiramatsu T, Ichimura A, Kimura I (2015) Dietary gut microbial metabolites, short-chain fatty acids, and host metabolic regulation. Nutrients 7:2839-2849. https://doi. org/10.3390/nu7042839

Kaur N, Gupta AK (2002) Applications of inulin and oligofructose in health and nutrition. J Biosci 27:703-714

Koeth RA et al (2013) Intestinal microbiota metabolism of L-carnitine, a nutrient in red meat, promotes atherosclerosis. Nat Med 19:576-585. https://doi.org/10.1038/nm.3145

Koeth RA et al (2014) Gamma-Butyrobetaine is a proatherogenic intermediate in gut microbial metabolism of L-carnitine to TMAO. Cell Metab 20:799-812. https://doi.org/10.1016/j.cmet.2014.10. 006

Kouchaki E et al (2017) Clinical and metabolic response to probiotic supplementation in patients with multiple sclerosis: a randomized, double-blind, placebo-controlled trial. Clin Nutr 36:12451249. https://doi.org/10.1016/j.clnu.2016.08.015

Kumar S, Stecher G, Tamura K (2016) MEGA7: molecular evolutionary genetics analysis version 7.0 for bigger datasets. Mol Biol Evol 33:1870-1874. https://doi.org/10.1093/molbev/msw054

Kummen $\mathrm{M}$ et al (2017) Elevated trimethylamine- $N$-oxide (TMAO) is associated with poor prognosis in primary sclerosing cholangitis patients with normal liver function. United Eur Gastroenterol J 5:532-541. https://doi.org/10.1177/2050640616663453

Lakio L et al (2006) Pro-atherogenic properties of lipopolysaccharide from the periodontal pathogen Actinobacillus actinomycetemcomitans. J Endotoxin Res 12:57-64. https://doi.org/10.1179/ 096805106X89099
LaRusso NF, Korman MG, Hoffman NE, Hofmann AF (1974) Dynamics of the enterohepatic circulation of bile acids. Postprandial serum concentrations of conjugates of cholic acid in health, cholecystectomized patients, and patients with bile acid malabsorption. N Engl J Med 291:689-692. https://doi.org/10. 1056/NEJM197410032911401

Lephart ED, Adlercreutz H, Lund TD (2001) Dietary soy phytoestrogen effects on brain structure and aromatase in Long-Evans rats. NeuroReport 12:3451-3455

Lepper PM et al (2011) Lipopolysaccharide-binding protein (LBP) is associated with total and cardiovascular mortality in individuals with or without stable coronary artery disease-results from the Ludwigshafen Risk and Cardiovascular Health Study (LURIC). Atherosclerosis 219:291-297. https://doi.org/10.1016/j. atherosclerosis.2011.06.001

Levi M (2016) Role of bile acid-regulated nuclear receptor FXR and G protein-coupled receptor TGR5 in regulation of cardiorenal syndrome (Cardiovascular Disease and Chronic Kidney Disease). Hypertension 67:1080-1084. https://doi.org/10.1161/ HYPERTENSIONAHA.115.06417

$\mathrm{Li} \mathrm{J}$ et al (2014) An integrated catalog of reference genes in the human gut microbiome. Nat Biotechnol 32:834-841. https://doi. org/10.1038/nbt.2942

Liber A, Szajewska H (2013) Effects of inulin-type fructans on appetite, energy intake, and body weight in children and adults: systematic review of randomized controlled trials. Ann Nutr Metab 63:42-54. https://doi.org/10.1159/000350312

Lin CJ et al (2014) p-Cresyl sulfate is a valuable predictor of clinical outcomes in pre-ESRD patients. Biomed Res Int 2014:526932. https://doi.org/10.1155/2014/526932

Louis $P$ et al (2004) Restricted distribution of the butyrate kinase pathway among butyrate-producing bacteria from the human colon. J Bacteriol 186:2099-2106

Louis P, Young P, Holtrop G, Flint HJ (2010) Diversity of human colonic butyrate-producing bacteria revealed by analysis of the butyryl-CoA: acetate CoA-transferase gene. Environ Microbiol 12:304-314. https://doi.org/10.1111/j.1462-2920.2009.02066.x

Louis P, Hold GL, Flint HJ (2014) The gut microbiota, bacterial metabolites and colorectal cancer. Nat Rev Microbiol 12:661672. https://doi.org/10.1038/nrmicro3344

Lu YC, Yeh WC, Ohashi PS (2008) LPS/TLR4 signal transduction pathway. Cytokine 42:145-151. https://doi.org/10.1016/j.cyto. 2008.01.006

Maclver DH, McNally PG, Ollerenshaw JD, Sheldon TA, Heagerty AM (1990) The effect of short-chain fatty acid supplementation on membrane electrolyte transport and blood pressure. J Hum Hypertens 4:485-490

Manrique Vergara D, Gonzalez Sanchez ME (2017) Short chain fatty acids (butyric acid) and intestinal diseases. Nutr Hosp 34:58-61. https://doi.org/10.20960/nh.1573

Mardis ER (2008) Next-generation DNA sequencing methods. Annu Rev Genomics Hum Genet 9:387-402. https://doi.org/10.1146/ annurev.genom.9.081307.164359

Martinez-del Campo A et al (2015) Characterization and detection of a widely distributed gene cluster that predicts anaerobic choline utilization by human gut bacteria. MBio. https://doi.org/10.1128/ mbio.00042-15 
Matthies A, Loh G, Blaut M, Braune A (2012) Daidzein and genistein are converted to equol and 5-hydroxy-equol by human intestinal Slackia isoflavoniconvertens in gnotobiotic rats. J Nutr 142:4046. https://doi.org/10.3945/jn.111.148247

Mayerhofer CCK et al (2017) Increased secondary/primary bile acid ratio in chronic heart failure. J Card Fail 23:666-671. https://doi. org/10.1016/j.cardfail.2017.06.007

Mendelson MM et al (2017) Association of Body Mass Index with DNA methylation and gene expression in blood cells and relations to cardiometabolic disease: a Mendelian randomization approach. PLoS Med 14:e1002215. https://doi.org/10.1371/ journal.pmed.1002215

Menze ET, Esmat A, Tadros MG, Abdel-Naim AB, Khalifa AE (2015) Genistein improves 3-NPA-induced memory impairment in ovariectomized rats: impact of its antioxidant, anti-inflammatory and acetylcholinesterase modulatory properties. PLOS ONE 10: e0117223. https://doi.org/10.1371/journal.pone.0117223

Meyer TW, Hostetter TH (2012) Uremic solutes from colon microbes. Kidney Int 81:949-954. https://doi.org/10.1038/ki.2011.504

Miettinen TA (1971) Relationship between faecal bile acids, absorption of fat and vitamin B 12, and serum lipids in patients with ileal resections. Eur J Clin Invest 1:452-460

Miller TL, Wolin MJ (1996) Pathways of acetate, propionate, and butyrate formation by the human fecal microbial flora. Appl Environ Microbiol 62:1589-1592

Mills EL et al (2018) Itaconate is an anti-inflammatory metabolite that activates Nrf2 via alkylation of KEAP1. Nature 556:113-117. https://doi.org/10.1038/nature25986

Miyamoto $\mathrm{J}$ et al (2016) The role of short-chain fatty acid on blood pressure regulation. Curr Opin Nephrol Hypertens 25:379-383. https://doi.org/10.1097/MNH.0000000000000246

Morito $\mathrm{K}$ et al (2001) Interaction of phytoestrogens with estrogen receptors alpha and beta. Biol Pharm Bull 24:351-356

Moss JW, Ramji DP (2016) Nutraceutical therapies for atherosclerosis. Nat Rev Cardiol 13:513-532. https://doi.org/10.1038/ nrcardio.2016.103

Nallu A, Sharma S, Ramezani A, Muralidharan J, Raj D (2017) Gut microbiome in chronic kidney disease: challenges and opportunities. Transl Res 179:24-37. https://doi.org/10.1016/j.trsl.2016. 04.007

Natarajan N et al (2016) Microbial short-chain fatty acid metabolites lower blood pressure via endothelial $\mathrm{G}$ protein-coupled receptor 41. Physiol Genomics 48:826-834. https://doi.org/10.1152/ physiolgenomics.00089.2016

Nilsson NE, Kotarsky K, Owman C, Olde B (2003) Identification of a free fatty acid receptor, FFA2R, expressed on leukocytes and activated by short-chain fatty acids. Biochem Biophys Res Commun 303:1047-1052

Oellgaard J, Winther SA, Hansen TS, Rossing P, von Scholten BJ (2017) Trimethylamine $N$-oxide (TMAO) as a new potential therapeutic target for insulin resistance and cancer. Curr Pharm Des 23:3699-3712. https://doi.org/10.2174/ 1381612823666170622095324

Paasche S (2013) Fecal microbiota transplantation: an innovative approach to treating Clostridium difficile disease. JAAPA 26:4649
Panigrahi $P$ et al (2017) A randomized synbiotic trial to prevent sepsis among infants in rural India. Nature 548:407-412. https:// doi.org/10.1038/nature23480

Pascal MC, Burini JF, Chippaux M (1984) Regulation of the trimethylamine $\mathrm{N}$-oxide (TMAO) reductase in Escherichia coli: analysis of tor: Mud1 operon fusion. Mol Gen Genet 195:351-355

Pereira-Fantini PM et al (2017) Unravelling the metabolic impact of SBS-associated microbial dysbiosis: insights from the piglet short bowel syndrome model. Sci Rep 7:43326. https://doi.org/10. $1038 /$ srep43326

Peterson $\mathrm{J}$ et al (2010) Dietary lignans: physiology and potential for cardiovascular disease risk reduction. Nutr Rev 68:571-603. https://doi.org/10.1111/j.1753-4887.2010.00319.x

Pluznick J (2014) A novel SCFA receptor, the microbiota, and blood pressure regulation. Gut Microbes 5:202-207. https://doi.org/10. 4161/gmic. 27492

Pluznick JL et al (2013) Olfactory receptor responding to gut microbiota-derived signals plays a role in renin secretion and blood pressure regulation. Proc Natl Acad Sci USA 110:44104415. https://doi.org/10.1073/pnas.1215927110

Porez G, Prawitt J, Gross B, Staels B (2012) Bile acid receptors as targets for the treatment of dyslipidemia and cardiovascular disease. J Lipid Res 53:1723-1737. https://doi.org/10.1194/jlr. R024794

Prohaszka L, Jayarao BM, Fabian A, Kovacs S (1990) The role of intestinal volatile fatty acids in the Salmonella shedding of pigs. Zentralbl Vet B 37:570-574

Qin J et al (2010) A human gut microbial gene catalogue established by metagenomic sequencing. Nature 464:59-65. https://doi.org/ 10.1038/nature08821

Radtke OA, Kiderlen AF, Kayser O, Kolodziej H (2004) Gene expression profiles of inducible nitric oxide synthase and cytokines in Leishmania major-infected macrophage-like RAW 264.7 cells treated with gallic acid. Planta Med 70:924-928. https://doi. org/10.1055/s-2004-832618

Raspor P, Goranovic D (2008) Biotechnological applications of acetic acid bacteria. Crit Rev Biotechnol 28:101-124. https://doi. org/10.1080/07388550802046749

Rath S, Heidrich B, Pieper DH, Vital M (2017) Uncovering the trimethylamine-producing bacteria of the human gut microbiota. Microbiome 5:54. https://doi.org/10.1186/s40168-017-0271-9

Rausch C, Lerchner A, Schiefner A, Skerra A (2013) Crystal structure of the omega-aminotransferase from Paracoccus denitrificans and its phylogenetic relationship with other class III aminotransferases that have biotechnological potential. Proteins 81:774-787. https://doi.org/10.1002/prot.24233

Reger MK, Zollinger TW, Liu Z, Jones J, Zhang J (2017) Association between urinary phytoestrogens and C-reactive protein in the continuous national health and nutrition examination survey. J Am Coll Nutr 36:434-441. https://doi.org/10.1080/07315724. 2017.1318722

Reichardt N et al (2014) Phylogenetic distribution of three pathways for propionate production within the human gut microbiota. ISME J 8:1323-1335. https://doi.org/10.1038/ismej.2014.14

Rothschild D et al (2018) Environment dominates over host genetics in shaping human gut microbiota. Nature 555:210-215. https:// doi.org/10.1038/nature25973 
Schuett $\mathrm{K}$ et al (2017) Trimethylamine- $N$-oxide and heart failure with reduced versus preserved ejection fraction. J Am Coll Cardiol 70:3202-3204. https://doi.org/10.1016/j.jacc.2017.10.064

Schuijt TJ et al (2016) The gut microbiota plays a protective role in the host defence against pneumococcal pneumonia. Gut 65:575583. https://doi.org/10.1136/gutjnl-2015-309728

Schumann RR et al (1990) Structure and function of lipopolysaccharide binding protein. Science 249:1429-1431

Seldin MM et al (2016) Trimethylamine $N$-oxide promotes vascular inflammation through signaling of mitogen-activated protein kinase and nuclear factor-kappaB. J Am Heart Assoc. https:// doi.org/10.1161/jaha.115.002767

Shan Z et al (2017) Association between microbiota-dependent metabolite trimethylamine- $\mathrm{N}$-oxide and type 2 diabetes. Am J Clin Nutr 106:888-894. https://doi.org/10.3945/ajcn.117.157107

Shi $\mathrm{J}$ et al (2015) Cleavage of GSDMD by inflammatory caspases determines pyroptotic cell death. Nature 526:660-665. https://doi. org/10.1038/nature15514

Shih DM et al (2015) Flavin containing monooxygenase 3 exerts broad effects on glucose and lipid metabolism and atherosclerosis. J Lipid Res 56:22-37. https://doi.org/10.1194/jlr.M051680

Stoclet JC, Kleschyov A, Andriambeloson E, Diebolt M, Andriantsitohaina R (1999) Endothelial no release caused by red wine polyphenols. J Physiol Pharmacol 50:535-540

Sun $X$ et al (2016) Trimethylamine $N$-oxide induces inflammation and endothelial dysfunction in human umbilical vein endothelial cells via activating ROS-TXNIP-NLRP3 inflammasome. Biochem Biophys Res Commun 481:63-70. https://doi.org/10.1016/j.bbrc. 2016.11.017

Suzuki T, Heaney LM, Bhandari SS, Jones DJ, Ng LL (2016) Trimethylamine $\mathrm{N}$-oxide and prognosis in acute heart failure. Heart 102:841-848. https://doi.org/10.1136/heartjnl-2015-308826

Suzuki T, Heaney LM, Jones DJ, Ng LL (2017) Trimethylamine Noxide and risk stratification after acute myocardial infarction. Clin Chem 63:420-428. https://doi.org/10.1373/clinchem.2016. 264853

Tang WH et al (2013) Intestinal microbial metabolism of phosphatidylcholine and cardiovascular risk. N Engl J Med 368:15751584. https://doi.org/10.1056/NEJMoa1109400

Tang WH et al (2015) Gut microbiota-dependent trimethylamine $N$ oxide (TMAO) pathway contributes to both development of renal insufficiency and mortality risk in chronic kidney disease. Circ Res 116:448-455. https://doi.org/10.1161/CIRCRESAHA.116. 305360

Tazoe $\mathrm{H}$ et al (2009) Expression of short-chain fatty acid receptor GPR41 in the human colon. Biomed Res 30:149-156

Tolhurst $\mathrm{G}$ et al (2012) Short-chain fatty acids stimulate glucagonlike peptide-1 secretion via the G-protein-coupled receptor FFAR2. Diabetes 61:364-371. https://doi.org/10.2337/db11-1019

Trieu VN, Uckun FM (1999) Genistein is neuroprotective in murine models of familial amyotrophic lateral sclerosis and stroke. Biochem Biophys Res Commun 258:685-688. https://doi.org/ 10.1006/bbrc.1999.0577

Troseid M et al (2015) Microbiota-dependent metabolite trimethylamine- $N$-oxide is associated with disease severity and survival of patients with chronic heart failure. J Intern Med 277:717-726. https://doi.org/10.1111/joim.12328
Tsuda T (2012) Dietary anthocyanin-rich plants: biochemical basis and recent progress in health benefits studies. Mol Nutr Food Res 56:159-170. https://doi.org/10.1002/mnfr.201100526

Tumur Z, Niwa T (2009) Indoxyl sulfate inhibits nitric oxide production and cell viability by inducing oxidative stress in vascular endothelial cells. Am J Nephrol 29:551-557. https://doi. org/10.1159/000191468

Tumur Z, Shimizu H, Enomoto A, Miyazaki H, Niwa T (2010) Indoxyl sulfate upregulates expression of ICAM-1 and MCP-1 by oxidative stress-induced NF-kappaB activation. Am J Nephrol 31:435441. https://doi.org/10.1159/000299798

Turnbaugh PJ et al (2006) An obesity-associated gut microbiome with increased capacity for energy harvest. Nature 444:10271031. https://doi.org/10.1038/nature05414

Ulman CA, Trevino JJ, Miller M, Gandhi RK (2014) Fish odor syndrome: a case report of trimethylaminuria. Dermatol Online J 20:21260

Vamanu E, Pelinescu D, Sarbu I (2016) Comparative fingerprinting of the human microbiota in diabetes and cardiovascular disease. J Med Food 19:1188-1195. https://doi.org/10.1089/jmf.2016. 0085

van der Schouw YT et al (2005) Prospective study on usual dietary phytoestrogen intake and cardiovascular disease risk in Western women. Circulation 111:465-471. https://doi.org/10.1161/01.CIR. $0000153814.87631 . B 0$

Vanharanta M et al (2002) Association between low serum enterolactone and increased plasma F2-isoprostanes, a measure of lipid peroxidation. Atherosclerosis 160:465-469

Vanharanta M, Voutilainen S, Rissanen TH, Adlercreutz H, Salonen JT (2003) Risk of cardiovascular disease-related and all-cause death according to serum concentrations of enterolactone: Kuopio Ischaemic Heart Disease Risk Factor Study. Arch Intern Med 163:1099-1104. https://doi.org/10.1001/archinte.163.9.1099

Vital M, Howe AC, Tiedje JM (2014) Revealing the bacterial butyrate synthesis pathways by analyzing (meta)genomic data. MBio 5: e00889. https://doi.org/10.1128/mBio.00889-14

Vonaesch P, Anderson M, Sansonetti PJ (2018) Pathogens, microbiome and the host: emergence of the ecological Koch's postulates. FEMS Microbiol Rev. https://doi.org/10.1093/femsre/ fuy003

Wahlstrom A, Sayin SI, Marschall HU, Backhed F (2016) Intestinal crosstalk between bile acids and microbiota and its impact on host metabolism. Cell Metab 24:41-50. https://doi.org/10.1016/j. cmet.2016.05.005

Wampach L et al (2017) Colonization and succession within the human gut microbiome by archaea, bacteria, and microeukaryotes during the first year of life. Front Microbiol 8:738. https://doi. org/10.3389/fmicb.2017.00738

Wang XL, Shin KH, Hur HG, Kim SI (2005) Enhanced biosynthesis of dihydrodaidzein and dihydrogenistein by a newly isolated bovine rumen anaerobic bacterium. J Biotechnol 115:261-269. https://doi.org/10.1016/j.jbiotec.2004.08.014

Wang Z et al (2011a) Gut flora metabolism of phosphatidylcholine promotes cardiovascular disease. Nature 472:57-63. https://doi. org/10.1038/nature09922

Wang Q, Zhang Y, Gao L, Xue Y (2011b) Effects of phytoestrogen, genistein combined with calcium and vitamin D3 on preventing 
osteoporosis in ovariectomized mice. Wei Sheng Yan Jiu 40:587590

Wang D et al (2012) Gut microbiota metabolism of anthocyanin promotes reverse cholesterol transport in mice via repressing miRNA-10b. Circ Res 111:967-981. https://doi.org/10.1161/ CIRCRESAHA.112.266502

Wang $Z$ et al (2014) Prognostic value of choline and betaine depends on intestinal microbiota-generated metabolite trimethylamine- $N$-oxide. Eur Heart J 35:904-910. https://doi.org/10.1093/ eurheartj/ehu002

Wang Z et al (2015a) Non-lethal inhibition of gut microbial trimethylamine production for the treatment of atherosclerosis. Cell 163:1585-1595. https://doi.org/10.1016/j.cell.2015.11.055

Wang $L$ et al (2015b) Methods to determine intestinal permeability and bacterial translocation during liver disease. J Immunol Methods 421:44-53. https://doi.org/10.1016/j.jim.2014.12.015

Ward HA, Kuhnle GG (2010) Phytoestrogen consumption and association with breast, prostate and colorectal cancer in EPIC Norfolk. Arch Biochem Biophys 501:170-175. https://doi.org/10. 1016/j.abb.2010.05.018

Ward HA et al (2010) Breast, colorectal, and prostate cancer risk in the European Prospective Investigation into Cancer and Nutrition-Norfolk in relation to phytoestrogen intake derived from an improved database. Am J Clin Nutr 91:440-448. https://doi.org/ 10.3945/ajcn.2009.28282

Warrier $M$ et al (2015) The TMAO-generating enzyme flavin monooxygenase 3 is a central regulator of cholesterol balance. Cell Rep. https://doi.org/10.1016/j.celrep.2014.12.036

Webster LT, Siddiqui UA, Lucas SV, Strong JM, Mieyal JJ (1976) Identification of separate acyl-CoA: glycine and acyl-CoA: Lglutamine $\mathrm{N}$-acyltransferase activities in mitochondrial fractions from liver of rhesus monkey and man. J Biol Chem 251:33523358

Wu IW et al (2012) Serum free p-cresyl sulfate levels predict cardiovascular and all-cause mortality in elderly hemodialysis patients-a prospective cohort study. Nephrol Dial Transplant 27:1169-1175. https://doi.org/10.1093/ndt/gfr453

Yang $T$ et al (2015) Gut dysbiosis is linked to hypertension. Hypertension 65:1331-1340. https://doi.org/10.1161/ HYPERTENSIONAHA. 115.05315

Yang K et al (2017) Indoxyl sulfate induces platelet hyperactivity and contributes to chronic kidney disease-associated thrombosis in mice. Blood 129:2667-2679. https://doi.org/10.1182/blood-2016$10-744060$
Yisireyili M et al (2013) Indoxyl sulfate promotes cardiac fibrosis with enhanced oxidative stress in hypertensive rats. Life Sci 92:11801185. https://doi.org/10.1016/j.lfs.2013.05.008

Yokota A et al (2012) Is bile acid a determinant of the gut microbiota on a high-fat diet? Gut Microbes 3:455-459. https://doi.org/10. 4161/gmic. 21216

Zdobnov EM et al (2017) OrthoDB v9.1: cataloging evolutionary and functional annotations for animal, fungal, plant, archaeal, bacterial and viral orthologs. Nucleic Acids Res 45:D744-D749. https:// doi.org/10.1093/nar/gkw1119

Zhang J, Wang YJ, Xu JL (2004) Experimental study on prevention and treatment of osteoporosis by phytoestrogen. Zhongguo Zhong Xi Yi Jie He Za Zhi 24:241-243

Zhang FM et al (2013) Fecal microbiota transplantation for severe enterocolonic fistulizing Crohn's disease. World J Gastroenterol 19:7213-7216. https://doi.org/10.3748/wjg.v19.i41.7213

Zhang M, Wang K, Chen L, Yin B, Song Y (2016) Is phytoestrogen intake associated with decreased risk of prostate cancer? A systematic review of epidemiological studies based on 17,546 cases. Andrology 4:745-756. https://doi.org/10.1111/andr.12196

Zhang $\mathrm{H}$ et al (2018) Indoxyl sulfate accelerates vascular smooth muscle cell calcification via microRNA-29b dependent regulation of Wnt/beta-catenin signaling. Toxicol Lett 284:29-36. https://doi. org/10.1016/j.toxlet.2017.11.033

Zhao $\mathrm{Y}$ et al (2016) Selenoprotein $\mathrm{P}$ neutralizes lipopolysaccharide and participates in hepatic cell endoplasmic reticulum stress response. FEBS Lett 590:4519-4530. https://doi.org/10.1002/ 1873-3468.12494

Zhao L et al (2018) Gut bacteria selectively promoted by dietary fibers alleviate type 2 diabetes. Science 359:1151-1156

Zhu $Y$ et al (2014) Carnitine metabolism to trimethylamine by an unusual Rieske-type oxygenase from human microbiota. Proc Natl Acad Sci USA 111:4268-4273. https://doi.org/10.1073/pnas. 1316569111

Zhu W et al (2016) Gut microbial metabolite TMAO enhances platelet hyperreactivity and thrombosis risk. Cell 165:111-124. https://doi.org/10.1016/j.cell.2016.02.011

Zhu W, Wang Z, Tang WHW, Hazen SL (2017) Gut microbegenerated trimethylamine $\mathrm{N}$-oxide from dietary choline is prothrombotic in subjects. Circulation 135:1671-1673. https://doi. org/10.1161/CIRCULATIONAHA.116.025338 